University of Nebraska - Lincoln

DigitalCommons@University of Nebraska - Lincoln

Biological Systems Engineering: Papers and

Publications

Biological Systems Engineering

$2-2016$

\title{
ECOSYSTEM EVAPOTRANSPIRATION: CHALLENGES IN \\ MEASUREMENTS, ESTIMATES, AND MODELING
}

D.M. Amatya

Suat Irmak

P. Gowda

G. Sun

J.E. Nettles

See next page for additional authors

Follow this and additional works at: https://digitalcommons.unl.edu/biosysengfacpub

Part of the Bioresource and Agricultural Engineering Commons, Environmental Engineering Commons, and the Other Civil and Environmental Engineering Commons

This Article is brought to you for free and open access by the Biological Systems Engineering at

DigitalCommons@University of Nebraska - Lincoln. It has been accepted for inclusion in Biological Systems

Engineering: Papers and Publications by an authorized administrator of DigitalCommons@University of Nebraska Lincoln. 
Authors

D.M. Amatya, Suat Irmak, P. Gowda, G. Sun, J.E. Nettles, and K.R. Douglas-Mankin 


\title{
ECOSYSTEM EVAPOTRANSPIRATION: CHALLENGES IN MEASUREMENTS, ESTIMATES, AND MODELING
}

\author{
D. M. Amatya, S. Irmak, P. Gowda, G. Sun, \\ J. E. Nettles, K. R. Douglas-Mankin
}

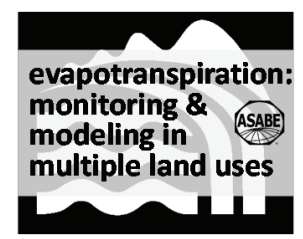

\begin{abstract}
Evapotranspiration (ET) processes at the leaf to landscape scales in multiple land uses have important controls and feedbacks for local, regional, and global climate and water resource systems. Innovative methods, tools, and technologies for improved understanding and quantification of ET and crop water use are critical for adapting more effective management strategies to cope with increasing demand for freshwater resources under global climate change. This article introduces an ASABE Special Collection of 12 articles on ET monitoring and modeling research for multiple land uses and scales. The collection focuses on recent advances in four critical topical areas: (1) reference ET (REF-ET) method development and applications, including crop management and irrigation scheduling, limitations due to sensor inaccuracies and variability, and sensitivity to climatic drivers (three articles); (2) ET process and pathway characterization, including canopy interception, transpiration, and soil evaporation measured using various state-of-the-art techniques on crop lands and plantation forests, and effects of soil moisture on grassland water balance (three articles); (3) ET simulation within hydrological models (SWAT, MIKE SHE, RZWQM, RZ-SHAW, RegCM-BATS, DRAINMODFOREST, and Thornthwaite water balance) as well as related processes, such as crop growth and ET/PET ratios, for grass, crop, and forest lands (four articles); and (4) geospatial technology applications, such as using remote sensing to estimate ET and its components (soil evaporation and transpiration) for various land uses (two articles). Study sites represent a range of spatial scales and ecohydrological settings, including grasslands in Inner Mongolia dry lands in northern China, semiarid high plains in Texas, corn production regions from Iowa to Colorado, forest plantations on the humid Atlantic Coastal Plain, developed coastal areas on the island of Taiwan, and the continental U.S. Results from these studies will help guide current development and assessment of REF-ET, ET, and monitoring and modeling of their components in multiple scales and ecosystems. The studies also establish a platform for addressing potential inaccuracies in data from weather sensors and algorithms used in remote sensing products for estimating ET and its parameters, including uncertainties in REF-ET estimates, for tall forest vegetation in particular. Furthermore, the studies offer insights into the interactions between climatic variability and change and vegetation through the ET process.
\end{abstract}

Keywords. Crop water use, Eddy flux, Interception, Potential evapotranspiration, Reference evapotranspiration, Remote sensing, Soil moisture, Transpiration.

$\mathrm{E}$ vapotranspiration (ET) is an important component of hydrological systems that regulates or influences runoff, soil water storage, groundwater recharge,

Submitted for review in February 2016 as manuscript number NRES 11808; approved for publication by the Natural Resources \& Environmental Systems Community of ASABE in April 2016.

Mention of company or trade names is for description only and does not imply endorsement by the USDA. The USDA is an equal opportunity provider and employer.

The authors are Devendra M. Amatya, ASABE Member, Research Hydrologist, USDA Forest Service, Center for Forested Wetlands Research, Cordesville, South Carolina; Suat Irmak, ASABE Member, Distinguished Professor, Department of Biological Systems Engineering, University of Nebraska-Lincoln, Lincoln, Nebraska; Prasanna Gowda, ASABE Member, Research Leader, USDA-ARS Grazinglands Research Laboratory, El Reno, Oklahoma; Ge Sun, Research Hydrologist, USDA Forest Service, Southern Research Station, Raleigh, North Carolina; Jami E. Nettles, Research Hydrologist, Weyerhaeuser Company, Columbus, Mississippi; Kyle R. Douglas-Mankin, ASABE Member, Surface Water Specialist, USGS New Mexico Water Science Center, Albuquerque, New Mexico. Corresponding author: Devendra Amatya, Center for Forested Wetlands Research, 3734 Highway 402, Cordesville, SC 29434; phone: 843-336-5612; e-mail: damatya@fs.fed.us. surface water availability, biodiversity, and the global climate system. Under widely varying climatic controls, ET is influenced by parameters that vary across a range of scales from local (e.g., soil, topography, vegetation type, snow cover, and localized weather conditions), to landscape (e.g., spatiotemporal heterogeneity of land use and management), to regional and/or global (e.g., spatiotemporal patterns of precipitation) (Amatya et al., 2014). ET processes at the smaller and medium scales (e.g., leaf to landscape) have important controls and feedbacks for regional and global climate systems through complex interactions among Earth's atmospheric, hydrological, and biogeochemical cycles. Forest clearing for urban expansion or tourism development, intensification of rural land uses for agriculture or bioenergy feedstock, and policy-driven changes in soil and water conservation practice implementation, for example, all affect the ET process and its pathways. Our ability to measure, estimate, and model ET, particularly at the watershed scale, is still limited. New, innovative methods, models, tools, technologies, and decision support systems (DSS) are emerging that advance our ability to quantify ET 
at scales ranging from single land use to complex ecosystems. Accurate estimates of ecosystem water use from irrigated agricultural and/or bioenergy crops to pine plantations at all scales will be critical for adapting more effective watershed management strategies to address increasing demands on water resources during times of increasing climatic variability and water supply stress.

This article serves to introduce a Special Collection of 12 articles, originally presented at the 2014 International Symposium "Evapotranspiration: Challenges in Measurement and Modeling from Leaf to the Landscape Scale and Beyond" organized by ASABE in April 2014 (Amatya et al., 2014). The following summaries of these 12 articles present key findings and highlight advances in knowledge across four key topical areas: reference ET (three articles), ET processes and pathways (three articles), modeling ET (four articles), and geospatial technology in estimating ET (two articles).

\section{REFERENCE EVAPOTRANSPIRATION}

Reliable and accurate daily reference ET (REF-ET) values are essential to estimate crop water demand for irrigation scheduling and hydrological modeling purposes. Gowda et al. (2016) present the Bushland REF-ET Calculator (BET), developed by the USDA-ARS Conservation and Production Research Laboratory and distributed at no cost. This is an addition to a suite of REF-ET calculators available in the literature, as it can be executed on desktop computers with any operating system. Simpler versions of the BET are available for smart phones with IOS and Android operating systems. The authors developed BET in response to a need identified by the ASCE Environmental and Water Resources Institute (EWRI) Evapotranspiration in Irrigation and Hydrology Committee during its 2010 annual meeting for a simple, user-friendly REF-ET calculator to assist producers and agronomic consultants with minimal or no training. The BET uses the ASCE-EWRI standardized Penman-Monteith (PM) equation (Monteith, 1965; Allen et al., 2005) for calculating single time step or time series grass and alfalfa REFET at hourly and daily time steps. Although the BET was designed and developed mainly for use by progressive producers and crop consultants to manage irrigation scheduling, it can also be used in educational training, research, and other practical applications.

Inaccuracies associated with weather station sensors may propagate measurement errors into REF-ET estimations. For example, an error of $25 \mathrm{~mm}$ in the total grass REF-ET (used to estimate corn ET) for the typical corn growing season (April to September) across the irrigated corn area within the Texas High Plains is approximately equivalent to the total drinking water consumption of the city of Houston for more than two months (Marek et al., 2010). Therefore, it is important for every weather station network to determine the relative effects of measurement errors in weather variables (air temperature, wind speed, solar radiation, and relative humidity) that are input to REF-ET estimates and develop sensor maintenance protocols. Moorhead et al. (2016) report and discuss results of sensitivity analyses of weather variables on daily REF-ET that were calculated using hourly data (1995-2008) from eight weather stations managed by the
Texas High Plains ET network in the Texas Panhandle (Marek et al., 2010). Given the advective conditions of the Texas High Plains, REF-ET was found to be most sensitive to wind speed. However, no significant differences in the sensitivity of REF-ET to any of the weather variables were found across the region, indicating that a uniform maintenance protocol should be sufficient for weather stations located throughout the Texas High Plains.

Investigating the sensitivity of REF-ET to climate drivers can enhance our understanding of implicit and explicit relationships between them and the response of REF-ET in different climatic regions. Hobbins (2016) applied secondmoment uncertainty analysis to a 30-year, continental U.S. (CONUS)-wide reanalysis of daily and annual tall-crop REFET as estimated by the ASCE Standardized REF-ET equation (Allen et al., 2005). The four input variables (air temperature, specific humidity, wind speed, and downward shortwave radiation) in the equation were obtained from the North American Land Data Assimilation System. The attribution methodology accounts for both the sensitivity of REFET to its drivers and their observed variabilities, and permits the decomposition of REF-ET $\left(\mathrm{ET}_{o}\right)$ variability across CONUS at various time scales into contributions from each driver. Analytically derived expressions of the sensitivity of daily ASCE Standardized REF-ET to each of the drivers are provided and mapped. The author concludes that, contrary to the assumption in much of the hydrological practice, temperature is not always the most significant driver of temporal variability in REF-ET, particularly at intra-annual time scales. Instead, depending on regional hydroclimatology, season, and time scale, different drivers dominate. In fact, in many regions, temperature-based parameterizations should be avoided at all time scales. While this study may provide additional information on the understanding of the response of REF-ET variability and sensitivity to climatic drivers, some of the climatic variables (e.g., wind speed) were simulated rather than measured. Thus, uncertainty remains as to how much of the variability in modeled (derived), rather than measured, climate variables can be expected to impact the variability and sensitivity of estimated $\mathrm{ET}_{0}$. In addition, the impacts of simulated versus measured climate data on $\mathrm{ET}_{o}$, as well as the interactions of hydroclimate, require further investigation.

\section{EVAPOTRANSPIRATION PROCESSES AND PARTITIONING}

Soil moisture is one of the key parameters controlling ecosystem ET (Shah et al., 2012; Verstaeten et al., 2008). Hao et al. (2016) characterized the variability of soil moisture dynamics and water balances in the temperate grassland ecosystems of Inner Mongolia in northern China from 1991 to 2012 by combining field monitoring and computer simulation using a physically based model, MIKE SHE. Soil moisture dramatically decreased at 50,70 , and $100 \mathrm{~cm}$ depths from the soil surface but not in the surface layer (0$50 \mathrm{~cm}$ depth) over the study period. They note that recent drought events and lack of heavy rainfall in the past decade caused the decreasing trend of soil moisture. Precipitation was the dominant component of the water balance in the 
grassland, and the balance between precipitation and ET explained the seasonal changes in soil water content. Persistent drought and change in precipitation patterns of decreasing large storm events, as well as total precipitation, were found to be the main causes for the observed drying trend in soils in the 2000s. Future studies should consider the impacts of regional groundwater overdraft on soil moisture for these grasslands as well as other ecosystems.

Partitioning of ET into evaporation (E) and transpiration (T) components can aid in evaluating the water use efficiency of a given crop production system and/or irrigation method including other ecosystem functions. Xiao et al. (2016) used an eddy covariance system to measure ET, sapflow gauges to measure $\mathrm{T}$, and heat-pulse sensors and soil sensible heat balance to measure soil E separately for 43 days during the corn growing season in Ames, Iowa. They also calculated corn ET (crop ET or $\mathrm{ET}_{c}$ ) using the crop coefficient and REF-ET approach. They observed that during the measurement period, E and T accounted for $13 \%$ and $87 \%$ of $\mathrm{E}+\mathrm{T}$, respectively, and $\mathrm{E}$ responded to variation in surface soil moisture and net radiation, whereas $T$ changed primarily with net radiation. All three ET estimation methods (individually measured $\mathrm{E}+\mathrm{T}$, eddy covariance $\mathrm{ET}$, and $\mathrm{ET}_{c}$ ) showed similar temporal trends and strong correlations $\left(\mathrm{R}^{2}=0.76\right.$ for crop $\mathrm{ET}_{c}$ vs. $\mathrm{E}+\mathrm{T} ; \mathrm{R}^{2}=0.77$ for $\mathrm{ET}$ vs. E+T) with the values of individually measured $\mathrm{E}+\mathrm{T}$ close to crop $\mathrm{ET}_{c}$ but larger than eddy covariance ET during the measurement period. Disparities in measurements were likely due to variations in measurement scale, which did not reflect the full range of field variability for individually measured $\mathrm{E}$ and $\mathrm{T}$, and to differences in response to declining soil water among the three approaches. Overall, the results support the need for individual measurement of each term (E, T, and ET) when attempting to interpret ET partitioning and suggest that soil heat-pulse sensors provide a viable complement to previously tested approaches for continuously determining E for ET partitioning during wetting and drying periods. The ET obtained from the sum of individually measured $\mathrm{E}$ and $\mathrm{T}$ (ranging from 0.4 to $6.9 \mathrm{~mm}$ $\mathrm{d}^{-1}$ ) as well as $\mathrm{ET}_{c}$ values (estimated using crop coefficients and REF-ET, ranging from 0.8 to $6.5 \mathrm{~mm} \mathrm{~d}^{-1}$ ) being greater than the eddy covariance ET (ranging from 0.3 to $5.8 \mathrm{~mm}$ $\mathrm{d}^{-1}$ ) can also be attributed to the well-known attribute of the eddy covariance method to underestimate latent heat flux (Wilson et al., 2002; Leuning et al., 2012), indicating the importance of vigorous calibration and validation procedures for any ET measurement method for various cropping systems in various climatic and management conditions.

Planted forest areas are expected to increase over $70 \%$ in the southern U.S. by 2060, and the consequences for forest water budgets are of concern to land managers and resource planners. Canopy interception of precipitation is an important component of ET in forested ecosystems. Gavazzi et al. (2016) conducted a long-term study to quantify canopy rainfall interception between 2005 and 2014 in a North Carolina coastal plain loblolly pine (Pinus taeda L.) plantation and determined the range of annual and seasonal variability in interception rates as influenced by stand thinning and natural variation in rainfall rates and intensities. The biweekly measured canopy interception rate averaged 19\% across all years and ranged from $14 \%$ to $23 \%$. The annual interception rate averaged $12 \%$ and ranged from $2 \%$ to $17 \%$. Thinning resulted in a $5 \%$ decrease in rainfall interception, but the interception rates quickly returned to prethin levels, likely due to rapid growth of the remaining trees. The long-term mean annual interception rate ranged from $2 \%$ to $24 \%$ with an average of $15 \%$ of total ET, consistent with earlier studies in another North Carolina coastal plain pine forest site (Amatya et al., 1996; Tian et al., 2012). The authors note that inter-annual variability of canopy interception is rather high, and short-term studies may not capture this variability.

\section{MODELING EVAPOTRANSPIRATION, ENERGY BAlance, ANd Related PARAMETERS}

ET is a primary component of hydrological balances in most ecosystems. Although numerous methods, including those reported above, have been developed to measure or quantify ET and its components, direct measurement of ET, in most cases, is not feasible. In such circumstances, validated ecohydrological simulation models may be viable alternatives to determine ET response in a variety of ecosystems. In some cases, calibration and validation of these models for simulating daily ET are done using measured streamflow only. Validations of ET simulated by these models against actual measured ET and/or its components are rarely done, largely due to unavailability of data on ET and its components, including irrigation databases for different cropping systems. Consequently, such a modeling approach may not necessarily provide reliable predictions of ET dynamics even though the modeled streamflow values match the observed data during the calibration period. Therefore, multiple measured parameters in addition to streamflow, such as ET and/or soil moisture or groundwater table, should also be used for a reliable comprehensive calibration and validation of watershed hydrology models.

Using long-term (2000-2010) lysimetric data, Marek et al. (2016) evaluated the SWAT model's simulation of daily, monthly, and seasonal ET for major irrigated crops (corn, sorghum, cotton, soybean, and sunflower) in the Texas High Plains. This is one of the most comprehensive evaluation studies to date on SWAT's ability to estimate ET. Cropwise comparison of simulated ET against observed data indicated that limitations in ET prediction accuracy existed for all crops at all time steps. This may be due to errors in the estimation of leaf area index (LAI) using the generic crop growth model embedded in SWAT. For example, SWAT underestimated daily and monthly ET and overestimated annual ET for cotton. This is due to overestimation of LAI for cotton during the senescing stage. Overall, the results indicated that SWAT can perform well for irrigated watersheds; however, limitations in accuracy exist for certain crops, such as cotton and sunflower, and particularly under limited-irrigation conditions.

Qi et al. (2016) used RZ-SHAW, a combination of the Root Zone Water Quality Model (RZWQM) and the Simultaneous Heat and Water model (SHAW), to evaluate model performance in simulating crop growth, soil water, surface 
energy balance components (including ET), and canopy temperature for full- and deficit-irrigated corn in eastern Colorado. Model simulations of ET were compared to ET measured with the Bowen ratio energy balance. The model simulated grain yield satisfactorily, with an error of less than $5 \%$ (380 $\mathrm{kg} \mathrm{ha}^{-1}$ difference between simulated and measured grain yields). Leaf area index, daily ET, soil water content, canopy temperature, and energy balance components (including net radiation, latent heat, sensible heat, and ground heat flux) were also simulated well, with coefficients of determination $\left(R^{2}\right) \geq 0.64$ and model efficiencies $\geq 0.57$ for both full- and deficit-irrigated fields. The root mean squared error between measured and simulated ET was $1.06 \mathrm{~mm} \mathrm{~d}^{-1}(1.6$ $\mathrm{mm} \mathrm{d}^{-1}$ maximum difference) for full irrigation and $0.96 \mathrm{~mm}$ $\mathrm{d}^{-1}$ for deficit irrigation. The RZ-SHAW model accurately predicted the responses of crop growth and ET to water stress, and the simulated water stress was in good agreement with the measured elevated canopy temperature with deficit irrigation after silking. Model performance was not acceptable in predicting plant height for water-stressed corn, nor in simulating differences in canopy temperature between fulland deficit-irrigated corn. The authors suggest that while RZSHAW can be used to evaluate the response of corn yield and water and energy balances to water stress, simulation of the effects of water deficit on plant height and canopy temperature needs further improvement. The results also indicate that while simulation models may perform adequately in predicting crop response to full and deficit irrigation, they can also result in large errors (up to $1.6 \mathrm{~mm} \mathrm{~d}^{-1}$ ) in estimating ET, indicating the need for vigorous calibration, especially if the models are intended to be used for within-season irrigation management.

Large-scale land cover change from abandoned farmland to forests has occurred in the western plain of Taiwan in the past decade, but its hydrometeorological effects are unknown. Liu et al. (2016) conducted a regional numerical simulation study using the National Center for Atmospheric Research regional climate model, RegCM (Giorgi et al., 1993) coupled with soil and vegetation during a summer monsoon season to evaluate the effects of land use changes on ET and related land surface processes. The study assumed that all crop lands are converted into forests. The afforestation was assumed to take place at grid points in the western plain with elevations of 500 $\mathrm{m}$ or lower. The authors found that maximum solar radiation was increased due to smaller albedo after afforestation, but maximum ET was decreased on clear days, mainly due to reduced wind speed within the forest canopies. Maximum sensible heat flux was increased due to the larger total vegetation area in forests than in former land uses. In contrast, ET was increased and sensible heat flux was decreased under rainy conditions. The authors conclude that changes in ET from afforestation are more important on clear days than on rainy days, and afforestation modulates hydrological cycles by reducing ET on clear days and elevating ET on rainy days.

Reliable estimates of potential ET (PET) in forest ecosystems are elusive, as PET both responds to and is controlled by complex vegetation, land use and climate change, water supply, and ecosystem restoration dynamics. Based on longterm on-site measured hydro-climatic data and predictions from earlier validated hydrological modeling studies, Amatya et al. (2016) compared several methods to estimate monthly and annual PET and ET for North Carolina (NC) and South Carolina (SC) Atlantic coastal plain forests. The Hargreaves-Samani (H-S) PET method (Hargreaves and Samani, 1985), which generally overestimates REF-ET, was also found to slightly overestimate forest reference-based PM PET (Amatya and Harrison, 2016). PET estimated with the H-S method was used in the Thornthwaite water balance model, which was validated with long-term monthly streamflow data to obtain simulated ET for the 1946-2008 period for a natural pine mixed hardwood forest at the SC site (Dai et al., 2013). The PM PET method was used in DRAINMOD-FOREST, which was validated with both daily streamflow and water table data for quantifying ET for the 1988-2008 period for a managed pine forest at the NC site (Tian et al., 2012). While the long-term mean seasonal values and variations in ET/PET ratios calculated using the simulated monthly ET values for the validation periods for both forested sites were reported to be similar, they were found to be different from the ET/REF-ET values and their seasonal distribution reported for another pine forest site in coastal NC using eddy flux-based measurements of ET. The results from this study, further supported by Amatya and Harrison (2016), showed a large difference in PET estimates from the different methods, particularly for grass and forest references. This study also highlights the importance of properly defining and estimating forest PET, rather than using REF-ET, and the uncertainty in estimating ET for forest hydrology models and water balance studies using the mean monthly ET/REF-ET ratio method.

\section{Geospatial Technology Applications IN ESTIMATING EVAPOTRANSPIRATION}

ET methods based on remote sensing show great advantages over conventional field methods in their ability to cover larger scales, and these methods have increasingly been used to estimate ET and related climatic and biophysical parameters in a rapid, accurate, and cost-effective manner (Irmak, 2012). Remote sensing data with increasing image resolution, together with basic measurements on the ground, especially micrometeorological measurements such as air temperature, relative humidity, solar radiation, and wind speed, have proven useful for simulating ET over various temporal and spatial scales. However, challenges remain due to the complexities and site-specific assumptions in the algorithms used for estimating parameters, such as aerodynamic resistance and surface resistance, as well as the challenges of accurate ground-truth validation. Panda et al. (2016) developed remote sensing based models for estimating ET and several biophysical parameters (canopy conductance, upper canopy temperature, and soil moisture) for a mature loblolly pine forest (Pinus taeda L.) in the Parker Tract of eastern North Carolina. To validate the remote sensing approach, they acquired long-term on-site eddy flux measurements, including micrometeorological variables, and water and en- 
ergy fluxes. The results suggest that the remote sensing approach has promise for estimating ET with good accuracy for a homogenous mature pine forest. Further work is needed to develop robust remote sensing based ET models by including spatial variability, sound data mining, high-resolution imagery, and advanced image processing to account for potential modeling uncertainties.

The three-temperature (3T) model, first published by Qiu in 1996, was reviewed by Yan and Qiu (2016). The model estimates soil evaporation (E) and vegetation transpiration (T) separately, which sum to provide ET with a normalized vegetation index. Necessary input parameters to estimate ET using energy balance equations with a transfer coefficient for each component are net radiation, soil heat flux, and soil, leaf canopy, and air temperatures, with no ground or canopy parameters needed to calculate surface and aerodynamic resistance as in other models. The transfer coefficients are calculated for a given time using the ratio of evaporating (drying) soil surface minus air temperature to dry soil surface minus air temperature for the E submodel and the ratio of evaporating (drying) leaf canopy minus air temperature to dry leaf canopy minus air temperature for the $\mathrm{T}$ submodel. There are challenges in modeling, especially in measuring dry soil and vegetation temperatures at larger scales, but the model has been applied and verified at multiple scales, from a growth chamber to the Heihe River basin (China). By using thermal remote sensing with ground-truth data and substituting maximum soil and vegetation temperatures for dry temperatures, the model showed good agreement with measured methods and more complex models. The ability to estimate and partition ET, from small controlled plots to large basins with great seasonal and spatial variation, make the $3 \mathrm{~T}$ model a promising tool for widespread use in research and practical applications.

\section{RECOMMENDATIONS AND FUTURE DiRECTIONS}

ET is an extremely complex surface energy balance process, and current understanding of the magnitude and degree of its interactions with many environmental factors is incomplete. The 12 studies included in this ASABE Special Collection provide insights into applications and limitations of globally used REF-ET methods for water management, crop irrigation scheduling, application in other ecosystems, ET processes and pathways, ET modeling and its interactions with influencing factors at various scales (field to continental scale), and remote sensing approaches to estimate and scale-up ET.

Future research should continue to enhance our limited understanding of the spatial and temporal variability and sensitivity of ET toward developing more robust models and measurement techniques to better evaluate hydrological balances and plant responses to ET at various scales, from field to continental scale. There are still large knowledge gaps in scaling up or down among plot, watershed, regional, and global spatial scales that warrant further research. For example, Budyko (1974) may provide a framework for an ecosystem-based ET modeling approach at multiple scales. Better characterization of the complex ecohydrological soilvegetation-atmosphere feedbacks of ET, including the widely used Penman-Monteith approach (Monteith, 1965), is needed to better understand the dynamics of crop water use and irrigation scheduling, plant species-level controls in forest management and bioenergy crop production, and changing atmospheric $\mathrm{CO}_{2}$ concentration. Similarly, knowledge on partitioning ET into transpiration or canopy and soil/litter evaporation components throughout the life cycle of various vegetation species, as well as their interactions with climate change and other large-scale disturbances (e.g., drought, fire, insects and disease, etc.), must be advanced. Both development of novel approaches for modeling ET and improvement of the existing approaches are needed for more accurate and robust multi-scale prediction of ET including for extreme climates, particularly droughts.

The eddy covariance technique developed during past three decades represents one of the major advances in water flux measurements. Various tower-based flux networks across the world allow us the rare opportunity to fully understand the coupled energy, water, and carbon cycles. Although errors in eddy covariance based measurements may limit their direct use for agricultural and silvicultural applications, they provide insight into the dynamic nature of ET and energy balance, and they are widely used for regional model validations. New technologies using scintillometry have potential to improve ET estimation accuracy. The Bowen ratio energy balance system remains a robust technique for use in agricultural and other systems. However, all these technologies need to be tested thoroughly in different climatologic environments. Although thermal remote sensing based applications may have a potential for regional and global ET modeling, more research is needed to develop operational ET remote sensing programs for developing and distributing ET maps for crop irrigation scheduling as well as other vegetation water use. Further development is needed for obtaining high spatiotemporal resolution images to capture the spatiotemporal variability in ET and related parameters within a field. In the near future, unmanned aerial vehicles may provide opportunities for precision agriculture, irrigation scheduling, and intensive plantations, although significant research and validation are needed before these methods are ready for practical application.

\section{ACKNOWLEDGEMENTS}

This article introduces 12 articles in the 2016 Special Collection on "Evapotranspiration: Monitoring and Modeling in Multiple Land Uses" published by the Natural Resources and Environmental Systems (NRES) Community of ASABE in this issue of Transactions of the ASABE and the next issue of Applied Engineering in Agriculture. The authors would like to thank the ASABE publications staff, associate and guest editors, and reviewers for their contributions to and timely management of the review process. The authors also wish to thank all the contributing authors for sharing their results, information, data, and tools and for advancing and enriching the current knowledge of ET processes and monitoring and modeling approaches in multiple land uses through each of 
the articles. The authors would also like to Dr. David Bosch, Research Engineer, USDA-ARS Southeast Watershed Research Center, Tifton, Georgia, for their valuable comments and suggestions for this article.

\section{REFERENCES}

Allen, R. G., Walter, I. A., Elliott, R. A., Howell, T. A., Itenfisu, D., Jensen, M. J., \& Snyder, R. L. (2005). The ASCE standardized reference evapotranspiration equation. Reston, VA: ASCE.

Amatya, D. M., \& Harrison, C. A. (2016). Grass and forest potential evapotranspiration comparison using five methods in the Atlantic Coastal Plain. J. Hydrol. Eng., 05016007. http://dx.doi.org/10.1061/(ASCE)HE.1943-5584.0001341

Amatya D. M., Skaggs, R. W., \& Gregory, J. D. (1996). Effects of controlled drainage on the hydrology of a drained pine plantation in the North Carolina coastal plains. J. Hydrol., 181(1-4), 211232. http://dx.doi.org/10.1016/0022-1694(95)02905-2

Amatya, D. M., Sun, G., Gowda, P., de Jong, C., Nettles, J. E., Basu, S., \& Irmak. S. (2014). Evapotranspiration: Challenges in measurement and modeling from leaf to the landscape scale and beyond. Post-symposium summary. Retrieved from http://elibrary.asabe.org/conference.asp? confid=cmmllsb2014

Amatya, D. M., Tian, S., Dai, Z., \& Sun, G. (2016). Long-term potential and actual evapotranspiration of two different forests on the Atlantic coastal plain. Trans. ASABE, 59(2), 647-660. http://dx.doi.org/10.13031/trans.59.11141

Budyko, M. I. (1974). Climate and life. New York, NY: Academic Press.

Dai, Z., Trettin, C. C., \& Amatya, D. M. (2013). Effects of climate variability on forest hydrology and carbon sequestration on the Santee Experimental Forest in coastal South Carolina. General Technical Report SRS-172. Raleigh, NC: USDA Forest Service Southern Research Station.

Gavazzi, M. G., Sun, G., McNulty, S. G., Treasure, E. A., \& Wightman, M. G. (2016). Canopy rainfall interception measured over ten years in a coastal plain loblolly pine (Pinus taeda L.) plantation. Trans. ASABE, 59(2), 601-610. http://dx.doi.org/10.13031/trans.59.11101

Giorgi, F., Marinucci, M. R., De Canio, G., \& Bates, G. T. (1993). Development of a second-generation regional 584 climate model (RegCM2): Part II. Convective processes and assimilation of lateral boundary conditions. Monthly Weather Rev., 121(10), 2814-2832. http://dx.doi.org/10.1175/15200493(1993)121<2814:DOASGR>2.0.CO;2

Gowda, P. H., Howell, T. A., Baumhardt, R. L., Porter, D. O., Marek, T. H., \& Nangia, V. (2016). A user-friendly interactive tool for estimating reference ET using ASCE-EWRI standardized Penman-Monteith equation. Appl. Eng. Agric., 32(3), (in press). http://dx.doi.org/10.13031/aea.32.11673

Hao, L., Sun, G., Liu, Y.-Q., Zhou, G. S., Wan, J. H., Zhang, L. B., Niu, J. L., Sang, Y. H., \& He, J. J. (2016). Evapotranspiration and soil moisture dynamics in a temperate grassland ecosystem in Inner Mongolia, China. Trans. ASABE, 59(2), 577-590. http://dx.doi.org/10.13031/trans.59.11099

Hargreaves, G. H., \& Samani, Z. A. (1985). Reference crop evapotranspiration from temperature. Appl. Eng. Agric., 1(2), 9699. http://dx.doi.org/10.13031/2013.26773

Hobbins, M. (2016). The variability of ASCE standardized reference evapotranspiration: A rigorous, CONUS-wide decomposition and attribution. Trans. ASABE, 59(2), 561-576. http://dx.doi.org/10.13031/trans.59.10975

Irmak, A. (Ed.) (2012). Evapotranspiration: Remote sensing and modeling. Rijeka, Croatia: InTech. http://dx.doi.org/10.5772/725
Leuning, R., van Gorsel, E., Massman, W. J., \& Isaac, P. R. (2012). Reflections on the surface energy imbalance problem. Agric. Forest Meteorol., 156, 65-74. http://dx.doi.org/10.1016/j.agrformet.2011.12.002

Liu, Y.-Q., Zhang, L. B., Hao, L., Sun, G., \& Liu, S.-C. (2016). Evapotranspiration and land surface process responses to afforestation in western Taiwan: A comparison between dry and wet weather conditions. Trans. ASABE, 59(2), 635-646. http://dx.doi.org/10.13031/trans.59.11110

Marek, T., Porter, D., Gowda, P., Howell, T., \& Moorhead, J. (2010). Assessment of Texas evapotranspiration (ET) networks. Final report to the Texas Water Development Board for Contract No. 0903580904. AREC Publication 201011-12. Amarillo, TX: Texas AgriLife Research and Extension Center.

Marek, G., Gowda, P. H., Evett, S. R., Baumhardt, R. L., Brauer, D. K., Howell, T. A., Marek, T. H., \& Srinivasan, R. (2016). Calibration and validation of the SWAT model for predicting daily ET over irrigated crops in the Texas High Plains using lysimetric data. Trans. ASABE, 59(2), 611-622. http://dx.doi.org/10.13031/trans.59.10926

Monteith, J. L. (1965). Evaporation and environment. Symp. Soc. Exp. Biol., 19, 205-234.

Moorhead, J. E., Gowda, P. H., Marek, G. H., Porter, D. O., \& Marek, T. H. (2016). Spatial uniformity in sensitivity coefficient of reference ET in the Texas High Plains. Appl. Eng. Agric., 32(3), (in press). http://dx.doi.org/10.13031/aea.32. 10940

Panda, S. S., Amatya, D. M., Sun, G., \& Bowman, A. (2016). Remote estimation of a managed pine forest evapotranspiration with geospatial technology. Trans. ASABE, 59, (in review).

Qi, Z., Ma, L., Bausch, W. C., Trout, T. J., Ahuja, L. R., Flerchinger, G. N., \& Fang, Q. X. (2016). Simulating maize production, water and surface energy balance, canopy temperature, and water stress under full and deficit irrigation. Trans. ASABE, 59(2), 623-633. http://dx.doi.org/10.13031/trans.59.11067

Qiu, G. Y. (1996). A new method for estimation of evapotranspiration. PhD diss. Tottori, Japan: Tottori University, United Graduate School of Agriculture Science.

Shah, N., Ross, M., \& Trout, K. (2012). Chapter 6: Using soil moisture data to estimate evapotranspiration and development of a physically based root water uptake model. In A. Irmak (Ed.), Evapotranspiration: Remote sensing and modeling (pp. 97-124). Rijeka, Croatia: InTech. http://dx.doi.org/10.5772/18040

Tian, S., Youssef, M. A., Skaggs, R. W., Amatya, D. M., \& Chescheir, G. M. (2012). DRAINMOD-FOREST: Integrated modeling of hydrology, soil carbon and nitrogen dynamics, and plant growth for drained forests. J. Environ. Qual., 41(3), 764782. http://dx.doi.org/10.2134/jeq2011.0388

Verstraeten, W. V., Veroustraete, F., \& Feyen, J. (2008). Assessment of evapotranspiration and soil moisture content across different scales of observation. Sensors, 8(1), 70-117. http://dx.doi.org/10.3390/s8010070

Wilson, K., Goldstein, A., Falge, E., Aubinet, M., Baldocchi, D., Berbigier, P., Bernhofer, C., . . V Verma, S. (2002). Energy balance closure at FLUXNET sites. Agric. Forest Meteorol., 113, 223-243. http://dx.doi.org/10.1016/S0168-1923(02)00109-0

Xiao, X., Sauer, T. J., Singer, J. W., Horton, R., Ren, T., \& Heitman, J. L. (2016). Partitioning evaporation and transpiration in a maize field using heat-pulse sensors for evaporation measurement. Trans. ASABE, 59(2), 591-599. http://dx.doi.org/10.13031/trans.59.11059

Yan, C., \& Qiu, G. (2016). The three-temperature model to estimate evapotranspiration and its partitioning at multiple scales: A review. Trans. ASABE, 59(2), 661-670. http://dx.doi.org/10.13031/trans.59.11087 